\title{
Preparation, Optimization, and Evaluation of Pellets Containing Mesalamine With Natural Gums For Colon Drug Delivery System
}

\author{
Rijawan Rajjak PATHAN ${ }^{* *}$, Aquil-ur-Rahim SIDDIQUI ${ }^{* *}$ (D)
}

Preparation, Optimization, and Evaluation of Pellets Containing Mesalamine With Natural Gums For Colon Drug Delivery System

\section{SUMMARY}

The purpose of the present work was to formulate colon-targeted mesalamine pellets containing gums of Moringa oleifera Lam. (MOG) and Cyamopsis tetragonolobus Taub. (CTG). Formulation of single stimuli mediated release is also difficult to target colon due to variation in the physiological condition, so in present work, $p H$ dependent and enzyme degradation mechanisms are being used to release of drug at the colonic site.

Extrusion and spheronization techniques were used for the preparation of pellets. For formulation optimization, factorial design study 32 was used for the selection of the optimized batch.

It was found that high ratio of solvent $80: 20$ and $10 \%$ and $7.5 \%$ concentration of MOG and CTG respectively produce optimized pellets showed good physical properties and release for F8M and F8C and after coating it showed in vitro release at the colonic condition and in vivo roentgenographic images for targeting.

As to say as advantages, spheronization and extrusion method was proved to have economized, whereas natural gums used to control release which added advantage as being as inert and biocompatible. This further formulation scope at industrial scales to reduce side effects of synthetic polymer and make it more biocompatible with the body.

Key Words: Mesalamine, pellets, Moringa oleifera gum, Cyamopsis tetragonolobus gum, in vivo colon targeting
Kolona Hedefli Doğal Sakız ve Mesalamin İçeren Pelletlerin Hazırlanması, Optimizasyonu ve Değerlendirilmesi

$\ddot{O Z Z}$

Bu çalı̧̧manın amacı Moringa oleifera Lam. (MOG) ve Cyamopsis tetragonolobus Taub. (CTG)' den elde edilen sakızlar içeren kolona hedefli mesalamin pelletlerinin hazırlanmasidır. Tekli uyaran aracıl salımın kolona hedefli olarak gerçekleştirilmesinin fizyolojik koşullardan dolayı zor olması nedeniyle salımın kolonda sağlanması için $p H$ ve enzime duyarl salım mekanizmalar kullanılmıştır. Pelletlerin hazirlanmasinda ekstrüzyon ve sferonizasyon teknikleri kullanimıştrr. Formülasyonun optimizasyonunda, optimize serinin seçimi için faktöriyel tasarım çalışması 32 kullanılmıştır. Yüksek çözücü oranı (80:20) ve MOG ve CTG'nin sirasiyla \%10 ve \%7.5 konsantrasyonlarda kullanıminin optimize pelletlerin elde edilmesini sağladığ saptanmıstır. Elde edilen optimize pelletler hedeflendirme için iyi fiziksel özellik göstermis ve F8M ve F8C formülasyonlar ve bunların kaplanmıs formülasyonları kolon ortamında iyi in vitro salım özelliği göstermiş ve in vivo röntgenografik görüntü vermiştir. Avantaj olarak söylemek gerekirse, sferonizasyon ve ekstrüzyon ekonomik açıdan avantaj să̆larken kontrollü salım sağlamak amacıyla kullanılan doğal kaynaklı sakızlar inert ve biyouyumlu yapıları ile avantaj sağlamıştır. Bu formülasyon, endüstriyel ölçeklerde sentetik polimerin yan etkilerini azaltıp vücutla daha biyouyumlu hale getirebilir.

Anabtar Kelimeler: Mesalamin, pelletler, Moringa oleifera zamkı, Cyamopsis tetragonolobus zamkı, in vivo kolon hedefleme.

'ORCID: 0000-0001-8706-0898, Department of Pharmaceutics, SBSPM's B.Pharmacy College, Ambajogai, Beed, India;

" ORCID: 0000-0001-8989-6680, Department of Pharmacognosy, Shri Bhagwan College of Pharmacy, Aurangabad, India 


\section{INTRODUCTION}

Ulcerative colitis (UC) is one of the inflammatory bowel diseases (IBD) developed at the colonic site results in various complications which affects the delivery of drugs at the colonic site with conventional formulation as the colon is the distal part of the gastrointestinal tract (GIT). Immediate release of drugs at the colonic site is quite difficult when taken orally, get maximum absorbed in upper GIT, and deficient concentration of drug remains available for direct effect at the affected colonic area. Colon targeting is essential to achieve an immediate therapeutic response for colon diseases like ulcerative colitis, Crohn's disease, colorectal cancer etc., by releasing the drugs at the target site (Lorenzo-Lamosa, Remunán-López, Vila-Jato, \& Alonso, 1998). Various approaches have been used to target drug at the colonic place, including coating with $\mathrm{pH}$-dependent polymer, the formation of a prodrug, conjugation with monoclonal antibodies, and biodegradable material (Sinha \& Kumria, 2001a). These recent approaches have numerous advantages like reduced dose, improved therapeutic effect, and reduced systemic side effects over the conventional methods.

In the present study, mesalamine is used as a drug to treat UC. In the last four decades, sulfasalazine has been used for the treatment of IBD. Sulfasalazine is a conjugate of mesalamine and sulfapyridine (Stolk, Rietbroek, Wiltink, \& Tukker, 1990). Mesalamine is released into the colon by breaking the azo bond of sulfasalazine by the reductase enzymes secreted by colonic bacteria and shows the therapeutic effect (Sinha \& Kumria, 2001b). As per the recent studies related to the use of sulfasalazine containing two moieties from that mesalamine shows potent effect in therapy, whereas sulfapyridine shows various adverse effects. Some research was carried out for the prevention of adverse effects of sulfapyridine because the administration of mesalamine alone without conjugation with sulfapyridine gets degraded in upper GI, and less concentration drug remains available for targeted effect at the colonic site. For protection the drug from gastric degradation and delivery of drug at a specific area to show potential results in the treatment of UC, various formulations have been designed to prevent mesalamine degradation at the upper part of GIT and to release at the infected area (Cao, Jin, Ding, Zhang, $\& \mathrm{Xu}, 2016)$. Previous work were carried out on mesalamine formulations like enemas (Hanauer, 1998; Kam, Cohen, Dooley, Rubin, \& Orchard, 1996; Safdi, 1997) capsule (Hanauer, 1993; Hanauer, 1998), matrix tablet (Friciu, 2013;Patel, Shah, Amin, \& Shah, 2009; Pawar \& Gautam, 2016; Tuğcu-Demiröz, Acartürk, Takka, \& Konuş-Boyunağa, 2004), minitablets (Mohanta, 2019) microparticle (Čalija, 2013; Kakar, Batra, \& Singh, 2013; Lorenzo-Lamosa, 1998) and also some pellets formulations (Bendas, Christensen, \& Ayres, 2010). All these formulations have advantages as well as some limitations which include, rectal administration providing sound impact as compared to oral administration and some difficulties for administration (patient compliance and local effect on limited area) respectively (Kam, 1996). Capsules and matrix tablets are monolithic systems; sometime drugs may release at the upper GIT due to rupturing of film or capsule shell, so to prevent these types of limitations, the multi-particulate approach for treatment of colitis is more promising release the drugs at the colonic site. Pellets have been used as multi-particulate dosage forms for a couple of decades (Isaac, 2018). Pellets as a drug delivery system shows various pharmaco-technical and therapeutic advantages due to their multi-particular nature, which includes good flowability, less friability, uniform size distribution, and ease of coating to release at the desired site. Therapeutic benefits include avoiding the risk of toxicity due to dose dumping and more minor irritation in GIT (AlHashimi, Begg, Alany, Hassanin, \& Elshaer, 2018).

Formulation of colon-specific mesalamine pellets with natural gums of Moringa oleifera (MOG) and Cyamopsis tetragonolobus (Guar gum/CTG), these gums contain polysaccharides which act as prebiotics (apart from its binding and release retarding properties) helpful for the growth of colonic microflora responsible for anti-inflammatory activity in IBD (Hedin, Whelan, \& Lindsay, 2007). These gums are readily available, non-toxic and biocompatible (Mohanta, 2019). Various polysaccharides are widely used 
as carriers for drugs to target colonic sites with the enzyme-dependent release (Sinha \& Kumria, 2001a). These gums are used previously as release retardants for various formulations. MOG used in curcumin matrix tablet (Singhal, Daud, Jarald, \& Showkat, 2012) and in hydrogel (Singh \& Kumar, 2018a, 2018b) to release drugs at the colonic site, whereas CTG is used in matrix tablets (Tuğcu-Demiröz, 2004), minitablet (Mohanta, 2019), and in microsphere of mebeverine to release the drugs at colonic site for treating IBD (Patel \& Amin, 2011). In the present study, these gums were used for the preparation of colon- specific pellets in the treatment of UC. MOG and CTG was not used till in pelletization, whereas gums like xanthan gum (Santos, Veiga, Pina, \& Sousa, 2004) and mastic gum is used earlier (Deshpande, Gowda, \& Mahammed, 2013).

In the present study, formulation of colon-specific pellets were prepared by the extrusion-spheronization technique which is one the most popular techniques for the preparation of pellets (Muley, Nandgude, \& Poddar, 2016). It has various advantages on other methods such as being a simple and easy technique for scaling-up, cost-effective, flexible in processing, and simple automation (Ige \& Gattani, 2012). Desired properties of pellets like sphericity, roundness, hardness, aspect ratio and release of drug were achieved by experimental design 32 depending on different variables and their responses. Mono release retarding coating layer is not sufficient for releasing of the drug at the colonic site to achieve the desired effect which can be rationalized and achieved with a further coating of pellets with a $\mathrm{pH}$-responsive polymer, which ensures the protection from the environment of upper GIT, which is not suitable for the mesalamine release (Pawar \& Gautam, 2016; Tuğcu-Demiröz, 2004). The coating of pellets was done in a fluidized bed coater with the enteric coating copolymer Poly(methacrylate acid, methylmethacrylate) 1:2 (Eudragit S 100) and evaluated for in vitro release and in vivo targeting studies for confirmation of release at colonic site. This formulation retarded the release of drug at the upper part of GIT with reproducible effects and showed more excellent target-specific release at the colonic site, confirmed with in-vitro release and in vivo roentgenographic study.

\section{MATERIAL AND METHODS}

\section{Materials}

Mesalamine was purchased from Research lab Fine chemical industries(Mumbai, India), Moringa oleifera gum collected from the plant after incision, Cyamopsis tetragonolobus gum(Guar gum) and Avicel-PH 101 were purchased from Research-lab Fine chemical industries (Mumbai, India), and Isopropyl alcohol (IPA) purchased from Loba Chemie (Mumbai, India). Deionized distilled water was used in the studies.

\section{Methods}

\section{Preparation of pellets}

Pellets containing mesalamine with MOG and CTG were prepared by extrusion and spheronization technique. Various formulations were made with design expert software version 12 , and the composition of formulations are shown in Table 1 and 2 for MOG and CTG, respectively. The composition of mesalamine and excipients for separate batches were accurately weighed, mixed uniformly, and water and Isopropyl alcohol in the specified ratios for the individual batches were added in sufficient amount, as wetting agents to form a wet mass. The wet mass of the formulation was passed through a single screw extruder of $1 \mathrm{~mm}$ apertures to obtain a uniform extrude at $80 \mathrm{rpm}$ operational speed at room temperature. Obtained extrudes were added in a spheronizer (Shakti, SSP120GMP) consisting of a $2 \mathrm{~mm}$ friction plate of cross-hatch grooves. Operating speed was set at $1000 \mathrm{rpm}$ for the duration of $10 \mathrm{~min}$ to obtain uniform shape pellets. After the spheronization process, the pellets were dried overnight at room temperature (Hamedelniel, Bajdik, \& Pintye-Hódi, 2010; Muley, Nandgude, \& Poddar, 2017). 
Table 1. Composition of Mesalamine pellets for MOG

\begin{tabular}{|c|c|c|c|c|c|c|c|c|c|}
\hline Composition in mg & F1M & F2M & F3M & F4M & F5M & F6M & F7M & F8M & F9M \\
\hline Mesalamine & 400 & 400 & 400 & 400 & 400 & 400 & 400 & 400 & 400 \\
\hline Avicel PH101 & 265 & 230 & 195 & 265 & 230 & 195 & 265 & 230 & 195 \\
\hline MOG & 35 & 70 & 105 & 35 & 70 & 105 & 35 & 70 & 105 \\
\hline Water: IPA & $90: 10$ & $90: 10$ & $90: 10$ & $85: 15$ & $85: 15$ & $85: 15$ & $80: 20$ & $80: 20$ & $80: 20$ \\
\hline
\end{tabular}

Table 2. Composition of Mesalamine pellets for CTG

\begin{tabular}{|c|c|c|c|c|c|c|c|c|c|}
\hline Composition in mg & F1C & F2C & F3C & F4C & F5C & F6C & F7C & F8C & F9C \\
\hline Mesalamine & 400 & 400 & 400 & 400 & 400 & 400 & 400 & 400 & 400 \\
\hline Avicel PH101 & 265 & 247 & 230 & 265 & 247 & 230 & 265 & 247 & 230 \\
\hline CTG & 35 & 52.5 & 70 & 35 & 52.5 & 70 & 35 & 52.5 & 70 \\
\hline Water: IPA & $90: 10$ & $90: 10$ & $90: 10$ & $85: 15$ & $85: 15$ & $85: 15$ & $80: 20$ & $80: 20$ & $80: 20$ \\
\hline
\end{tabular}

\section{Factorial design}

A 32 full factorial design was used in stat ease design expert software version 12 for optimization and selection of batch with the sound effect. In the factorial study for MOG, the independent variables were different concentrations of MOG(A) and the ratio of wetting solvent Water: IPA (B), each at three different levels $(-1,0,+1)$, as shown in Table 3 and for the factorial study for CTG, the independent variables were different concentrations of CTG(A) and the ratio of wetting solvent Water: IPA (B), each at three different levels $(-1,0,+1)$, as shown in Table 4 .
The dependent variables for both gums studied were drug release $\%$, yield $\%$, hardness, sphericity and roundness. For the optimization of formulation by using experimental design, nine batches of each gum of pellets formulation were prepared. Responses were observed with different concentrations of MOG of $5 \%, 10 \%$, and $15 \%$ and the ratio of wetting liquid water and IPA of 90:10 to 80:20, and the same for CTG as per preliminary data of $5 \%, 7.5 \%$, and $10 \%$ were selected as shown in Tables 3 and 4 (Hamedelniel, 2010; Joshi, Pund, Nivsarkar, Vasu, \& Shishoo, 2008).

Table 3.Factorial studies for MOG

\begin{tabular}{|c|c|c|c|c|}
\hline Factor & Name & Level(-1) & Level(0) & Level $(+1)$ \\
\hline A & Concentration of MOG & $5 \% \mathrm{w} / \mathrm{w}$ & $10 \% \mathrm{w} / \mathrm{w}$ & $15 \% \mathrm{w} / \mathrm{w}$ \\
\hline B & Ratio of Water:IPA & $90: 10 \% \mathrm{v} / \mathrm{v}$ & $85: 15 \% \mathrm{v} / \mathrm{v}$ & $80: 20 \% \mathrm{v} / \mathrm{v}$ \\
\hline
\end{tabular}

Table 4.Factorial study for CTG

\begin{tabular}{|c|c|c|c|c|}
\hline Factor & Name & Level(-1) & Level $(0)$ & Level $(+1)$ \\
\hline A & Concentration of CTG & $5 \% \mathrm{w} / \mathrm{w}$ & $7.5 \% \mathrm{w} / \mathrm{w}$ & $10 \% \mathrm{w} / \mathrm{w}$ \\
\hline B & Ratio of Water:IPA & $90: 10 \% \mathrm{v} / \mathrm{v}$ & $85: 15 \% \mathrm{v} / \mathrm{v}$ & $80: 20 \% \mathrm{v} / \mathrm{v}$ \\
\hline
\end{tabular}

\section{Coating of pellets}

Coating of pellets was performed in a fluidized-bed coater (ACG Pharma Technology Pvt. Ltd.). $10 \mathrm{gm}$ sample of pellets was used for coating purposes. Coating dispersion was optimized on a trial-and-error basis and prepared by dissolving $10 \% \mathrm{w} / \mathrm{v}$ Eudragit S100 in the mixture of IPA: water
(90:10). Dibutyl phthalate $5 \%$ (w/ w related to the dry weight of polymer) was added directly to the polymer dispersions as a plasticizer. Finally, $5 \% \mathrm{w} / \mathrm{w}$ of talc as a glidant and titanium dioxide as an opaquant extender was added. The processing parameters were set for coating, temperature for inlet air was set at 40 ${ }^{\circ} \mathrm{C}$, and the temperature for outlet was 25 to $35^{\circ} \mathrm{C}$. 
The atomization pressure was set at 2.0 bars, and the spraying of coating dispersion was done with a single spray with an internal diameter of $0.5 \mathrm{~mm}$ at the rate of $0.5 \mathrm{~mL} / \mathrm{min}$. The process was continued to achieve a $10 \%(w / w)$ weight gain. Spraying was stopped after the desired coating was achieved, and pellets were fluidized in a coater for an additional 30 minutes for drying (The level of the coating was selected as per the literature survey for the proper release of drug at the colonic site) (Hamedelniel and Pintye-Hodi 2011; Kaffash et al. 2019).

\section{Compatibility study}

\section{Differential scanning calorimetry (DSC)}

For determination of compatibility or chemical interaction, a DSC study of pure Mesalamine, MOG, CTG, and pellets was performed to find changes after the formation of pellets. DSC thermograms were obtained using a SHIMADZU Crio-DSC (Japan). 10 $\mathrm{mg}$ of hermetically sealed sample was placed in the sample holder and heated at a heating rate of $20^{\circ} \mathrm{C} /$ min from $0^{\circ} \mathrm{C}$ to- $300^{\circ} \mathrm{C}$, and all thermograms were compared (Liu, Fishman, Kost, \& Hicks, 2003; Tho, Sande, \& Kleinebudde, 2002). Characteristic peaks were recorded, and the specific heat of the melting endotherm was evaluated. At least a duplicate was carried out for each sample and the mean of the results were used. Thermal properties were analyzed for retrogradation and gelatinization (Shaikh \& Kale, 2020).

\section{Fourier-transform infrared (FTIR) spectroscopy}

The powder sample of the Mesalamine, MOG, CTG, Avicel PH101, physical mixture and formulation pellets of MOG and CTG were kept at $500^{\circ} \mathrm{C}$ in the oven for drying for about $24 \mathrm{~h}$ to remove moisture content. After drying of powder, a sample of mesalamine was then mixed with $\mathrm{KBr}$ at $1: 100$ by using a mortar and pestle. Samples of other excipients MOG, CTG, and Avicel PH101 were taken to determine the compatibility of the drug with gums and other excipients used in the formulation. FTIR spectra at a wavelength ranged from 400 to $4000 \mathrm{~cm}-1$ was recorded using an FTIR spectrophotometer with the resolution of $4 \mathrm{~cm}-1$ (SHIMADZU DR-8031, Japan) (Kaffash, 2019; Muley, 2017; Singh, Reddy, \& Khan, 1996).

\section{Physical properties evaluation}

\section{Yield \%}

The yield $\%$ of pellets prepared by extrusion and spheronization were calculated by using the following formula:

$$
\text { Yield } \%=\frac{\text { Practical Yield }}{\text { Theoretical Yield }} X 100
$$

\section{Hardness}

The digital pellet hardness tester was used to check the hardness of pellets (Veego 01/0110). A single pellet was placed into the rotating anvil and base of hardness tester, the value was set at zero, and screw moved till pellet was broken. This procedure was repeated three times for precision (Muley, 2017).

\section{Pellet evaluation}

\section{Sphericity, aspect ratio, and roundness}

Pellets' images were captured and analyzed by ImageJ software to find the area $(A)$, longest $\left(\mathrm{d}_{\text {max }}\right)$, and shortest $\left(\mathrm{d}_{\text {min }}\right)$ diameters and perimeter $(\mathrm{P})$, and three shape factors, sphericity, roundness, and aspect ratio, were calculated by following formulas:

$$
\begin{aligned}
& \text { Sphericity }=\frac{4 \pi A}{P^{2}} \\
& \text { Roundness }=\frac{P^{2}}{4 \pi A} \\
& \text { Aspectratio }=\frac{d \text { max }}{d \min }
\end{aligned}
$$

Where $\mathrm{A}$ is an area, $\mathrm{P}$ is the perimeter, dmax is the longest, and dmin is the shortest diameter of the pellets. For sphericity values range from 0 to 1 , poor spherical value is 0 , and perfect sphere shows a value equal to 1 , and for roundness value close to 1 indicates more smooth and a value greater than $1.20 \mathrm{ob}-$ served not that much smooth (Hileman, Goskonda, Spalitto, \& Upadrashta, 1993; Kaffash, 2019; Mezreb, Charrueau, Boy, Allain, \& Chaumeil, 2004; Paterakis, Korakianiti, Dallas, \& Rekkas, 2002). 


\section{Scanning electron microscopy (SEM)}

SEM imaging was done to confirm the surface texture of the pellets sample. As per standard procedure, pellets sample was coated with a thin layer of gold under vacuum on SEM stub and sample stub kept in SEM analyzing chamber, operated at $10 \mathrm{kV}$ and run samples at different magnification (Supra 55, Carl Zeiss, German) (Auriemma, 2013; Pund, Joshi, Vasu, Nivsarkar, \& Shishoo, 2010).

\section{Drug content}

Mesalamine pellets were weighed accurately theoretically, equivalent to $100 \mathrm{mg}$ of drug and crushed to a fine powder in a mortar and dissolved in a $100 \mathrm{~mL}$ solution ( $5 \mathrm{~mL} 0.1 \mathrm{~N} \mathrm{HCl}+95 \mathrm{~mL} \mathrm{PBS})$ and sonicated for $30 \mathrm{~min}$. Dilution was made twice with $1 \mathrm{~mL}$ in 10 $\mathrm{mL}$ of phosphate buffer saline $0.05 \mathrm{M}$ in a $10 \mathrm{~mL}$ volumetric flask. The absorbance of the solution measured at $330 \mathrm{~nm}$ using an UVspectrophotometer (Shimadzu 1800). Absorbance values obtained from the analyses were used for the calculation of drug content (Kakar, 2013).

Drug content of pellets in triplicate was determined by using the following formula (eq.no.5)

$$
\% \text { Drugcontent }=\frac{\text { Experimentaldrugcontent }}{\text { Theoreticaldrugcontent }} \times 100
$$

\section{Drug Release of Uncoated Pellets}

Drug release studies of all formulations of uncoated pellets of MOG and CTG was performed by placing pellets theoretically equivalent to $100 \mathrm{mg}$ mesalamine into USP Type-I apparatus of dissolution tester (Electrolab). The dissolution medium of $900 \mathrm{~mL}$ of $0.1 \mathrm{~N} \mathrm{HCl}$ was kept at $37.0 \pm 0.5^{\circ} \mathrm{C}$. Basket's rotational speed was set at $75 \mathrm{rpm}$. A sampling of $5 \mathrm{~mL}$ medium was done at $15 \mathrm{~min}$ intervals and replaced with $5 \mathrm{~mL}$ of fresh medium. Testing was conducted for up to 2 hours analyzed on U.V. Spectrophotometer at $303 \mathrm{~nm}$ wavelength (Shimadzu 1800).

Release kinetics of formulation were determined by plotting release data with various release patterns such as Higuchi, Hixson Crowell, Korsmeyer Peppa's, zero-order, and first-order (Auriemma, 2013; Costa, Sousa, Pais, \& Formosinho, 2003; Ige \& Gattani, 2012).

\section{Drug release of coated pellets}

Dissolution tests of enteric-coated pellets were performed in a dissolution tester by placing pellets theoretically equivalent to $100 \mathrm{mg}$ mesalamine into the USP Type-I apparatus basket of dissolution tester (Electrolab). The dissolution media of $900 \mathrm{~mL}$ of $0.1 \mathrm{~N} \mathrm{HCl}$ was kept at $37.0 \pm 0.5^{\circ} \mathrm{C}$. Baskets rotational speed was set at $75 \mathrm{rpm}$. A sampling of $5 \mathrm{~mL}$ medium was done at $15 \mathrm{~min}$ intervals and replaced with $5 \mathrm{~mL}$ of fresh medium up to 2 hours analyzed on U.V. Spectrophotometer at $303 \mathrm{~nm}$ wavelength (Shimadzu 1800). The followed by replacing dissolution media and performed release study for $2 \mathrm{~h}$ in phosphate buffer $\mathrm{pH} 6.8$ and $4 \mathrm{~h}$ at phosphate buffer $\mathrm{pH} 7.4$ sample analyzed on U.V. Spectrophotometer at $330 \mathrm{~nm}$ wavelength (Shimadzu 1800) (Quinteros, Manzo, \& Allemandi, 2010; Stolk, 1990; Tuğcu-Demiröz, Acartürk, Takka, \& Konuş-Boyunağa, 2007).

\section{In vivo roentgenographic study}

An in vivo roentgenographic study was performed for the evaluation of colon targeting. The in vivo study was carried out on New Zealand white rabbits. Six male rabbits weighing 2-2.5 kg were used, and protocol for the animal study was approved from All procedures for in vivo studies were approved by the Institutional Animal Ethical Committee (IAEC) of SBSPM's B.Pharmacy college, Ambajogai (SBSPM/BPHARM/ IAEC/2020-21/01) and the care and use of animals was following the guidelines of the committee for the purpose of control and supervision of experiments on animals (CPCSEA), Ministry of fisheries, animal husbandry, and dairying (MoFAH \&D) Government of India. Pellet formulations with same composition with optimized batch F8M and F8C, 50\% drug replaced with radio-opaque substance barium sulfate and formulated with the same method described for pellets and further coating with eudragit S100 was done with the same procedure mentioned for coating. After overnight fasting, the pellets containing a radio-opaque substance were filled in size 5 hard gelatin capsules and administered to rabbits using an oral capsule injector with a flushing of $20 \mathrm{~mL}$ of water. 
Siemens X-Ray machine was used for X-Ray images for targeting study. The rabbit was placed in a prone position for the imaging process. The $\mathrm{X}$-ray images were taken at the time interval of $1,2,3,4,5,7$, and 8 h. (Parmar, Parikh, Mundada, Bhavsar, \& Sawant, 2018; Singh \& Pathak, 2015).

\section{Statistical analysis}

The results of the study are presented as mean \pm Standard deviation (SD). For optimization study of different variables and their the comparison, one-way ANOVA was used in Design expert software. A $P$ value $<0.05$ was considered to be significant for comparison of varying formulation batches.

\section{RESULTS}

\section{Compatibility study}

\section{FT-IR}

Determination of compatibility is done with FTIR studies of drug and excipient as shown in supplementary file page number S1-S4. In the IR spectrum of mesalamine, functional groups observed that $\mathrm{C}=\mathrm{O}$ carbonyl $\left(1618.33 \mathrm{~cm}^{-1}\right), \mathrm{C}-\mathrm{N}$ amine $(1354.07 \mathrm{~cm}$ $\left.{ }^{1}\right)$, C-O alcohol $\left(1136.11 \mathrm{~cm}^{-1}\right), \mathrm{C}-\mathrm{H}$ aromatic outof-plane bending $\left(794.70 \mathrm{~cm}^{-1}\right)$, and $\mathrm{C}-\mathrm{H}$ aromatic stretching $\left(3099.71 \mathrm{~cm}^{-1}\right)$, which are the functional groups of mesalamine. The observed frequencies, in 1618 and $1136 \mathrm{~cm}^{-1}$, were attributed carboxylic group and alcoholic group, respectively.

\section{DSC}

DSC curves for drug and formulation showed in supplementary files S4-S7. The pure mesalamine showed a sharp endothermic peak at $288.89^{\circ} \mathrm{C}$ that indicates the melting point of mesalamine. MOG showed a broad peak at $223.41^{\circ} \mathrm{C}$ with an onset of $209.32^{\circ} \mathrm{C}$ and an end set of $244.92^{\circ} \mathrm{C}$. CTG showed a broad peak at $220^{\circ} \mathrm{C}$ up to $280^{\circ} \mathrm{C}$. Pellets of MOG showed a peak at $283.98^{\circ} \mathrm{C}$, and pellets of CTG showed a shorter peak at $288.36^{\circ} \mathrm{C}$, unlike pellets MOG.

\section{Optimization studies}

The preliminary investigations were done for selection of upper and lower limit of concentration of gums and ratio of wetting liquid on a trial-and-error basis depending upon the uniform shape and mechanical strength of pellets. The lower limit for both gums was found 5\%, and the upper limit was found to be $10 \%$ and $15 \%$ for CTG and MOG, respectively, and water: IPA ratio was found to be 90:10 and 80:20 after critical examination of upper and lower limit respectively as mentioned in Tables 3 and 4 .

For final optimization of formulation and in-depth investigation of the effect of independent variables on responses was done by experimental design technique $3^{2}$ on DOE software. The factorial study was carried out to find a significant effect of most influencing factors; those are the different concentrations of gums and wetting liquid on responses include release, yield, sphericity, roundness, and hardness, as mentioned in Table 5 and 6 . The study was performed to the selection of the best levels of independent variables, and on that basis, the final optimized formulation batch was selected. Nine batches were made with each gum, and all responses were observed, which were fitted in a different model. From that basis, we found the optimum level of an independent variable. In optimization studies, various polynomial equations were obtained, as shown in table S7 of supplementary file for a relationship of factor, and responses. The positive sign indicates a synergistic effect, and the negative sign shows the antagonistic effect (Bodea \& Leucuta, 1997). As discussed above, IPA is added to water to reduce hydration of both gums. Effect in hydration change by adding IPA can be graphically represented by response surface curve as shown in Figures 1 and 2. It can be clearly understood by the $3 \mathrm{D}$ bar chart provided in supplementary file S7-S9. As per the graph (Figure $1 \& 2$ ), the effect of different ratios of IPA and concentrations of gums on various properties of pellets; \% yield, hardness, roundness, sphericity, aspect ratio, and \% drug release.

Effect of independent variables on the various parameters, firstly hardness of pellets formulation, according to both curves, it revealed that when the concentration of IPA increases, hardness of pellets decreases as observed in F7M, F8M and F9M batches showed $0.24 \pm 0.013,0.181 \pm 0.023$ and $0.181 \pm 0.023$ 
respectively which is low in hardness in contrast, the lower concentration of IPA formulation F1M, F2M and F3M showed $0.456 \pm 0.024,0.463 \pm 0.011$ and $0.517 \pm 0.052$ respectively which is higher hardness.

These formulations are also proportionally affected in terms of hardness to the concentration of gums - the concentration of MOG increases, hardness increases and when concentration decreases, vice versa. Higher hardness in F3M and F6M, and lower hardness was observed in F1M, F4M, and F7M shown in Tables 5, and 6 .

Sphericity close to 1 indicates that more spherical particles and values less than 1 indicate less spherical at an optimum concentration of gum and IPA indicated that good sphericity $0.9 \pm 0.052$ and $0.982 \pm 0.010$ for formulation F8M and F9C respectively and roundness less than 1.20 indicates smooth surface for identical batches $1.11 \pm 0.068$, and $1.01 \pm 0.026$. According to the optimization study, sphericity is more affected with the concentration of gum and ratio of solvent, at a moderate concentration of gum and high concentration of IPA showed good sphericity, roundness, and aspect ratio, it observed in formulation F8M and F9C $0.9 \pm 0.052$ and $0.982 \pm 0.010$ and roundness $1.11 \pm 0.068$ and $1.01 \pm 0.026$ respectively also it is shown that more effect of concentration solvent it followed that in batch F7M, F8M and F9M also same observation for gaur gum pellets in F7C and F8C only in F9C show less sphericity may be due to high concentration of gum and decreasing concentration of IPA shows less sphericity and roundness as per the observation of all factors and responses optimized formulation F8M and F8C were selected for the coating to achieve targeted release at colonic site. All these properties included sphericity, roundness, and aspect ratio for smooth coating.

Table 5. Evaluation results for optimization batches of pellets MOG

\begin{tabular}{|c|c|c|c|c|c|c|c|c|}
\hline Run & $\begin{array}{c}\text { Conc. of } \\
\text { MOG }\end{array}$ & $\begin{array}{c}\text { Water: } \\
\text { IPA }\end{array}$ & $\begin{array}{c}\text { Yield } \\
\mathbf{\%}\end{array}$ & $\begin{array}{c}\text { Hardness } \\
\mathbf{K g} / \mathbf{c m}^{\mathbf{2}}\end{array}$ & Sphericity & Roundness & Release & $\begin{array}{c}\text { Aspect } \\
\text { ratio }\end{array}$ \\
\hline 1 & -1 & -1 & 85.23 & 0.456 & 0.712 & 1.4 & 94.11 & 1.05 \\
\hline 2 & 0 & -1 & 91.14 & 0.463 & 0.721 & 1.38 & 88.12 & 1.03 \\
\hline 3 & 1 & -1 & 88.57 & 0.517 & 0.705 & 1.41 & 87.01 & 1.06 \\
\hline 4 & -1 & 0 & 86.28 & 0.314 & 0.709 & 1.4 & 91.94 & 1.04 \\
\hline 5 & 0 & 0 & 75.28 & 0.154 & 0.837 & 1.19 & 99.05 & 1.28 \\
\hline 6 & 1 & 0 & 74.71 & 0.532 & 0.889 & 1.12 & 89.1 & 1.17 \\
\hline 7 & -1 & 1 & 85.85 & 0.24 & 0.812 & 1.23 & 90.34 & 1.1 \\
\hline 8 & 0 & 1 & 86.42 & 0.181 & 0.9 & 1.11 & 90.94 & 1.3 \\
\hline 9 & 1 & 1 & 79.57 & 0.181 & 0.801 & 1.24 & 87.4 & 1.04 \\
\hline
\end{tabular}

Table 6. Evaluation results for optimization batches of pellets CTG

\begin{tabular}{|c|c|c|c|c|c|c|c|c|}
\hline Run & Conc. of CTG & Water: IPA & Yield \% & $\begin{array}{c}\text { Hardness } \\
\mathrm{Kg} / \mathrm{cm}^{2}\end{array}$ & Sphericity & Roundness & Release & Aspect ratio \\
\hline 1 & -1 & -1 & 55.85 & 0.273 & 0.715 & 1.37 & 96.11 & 1.11 \\
\hline 2 & 0 & -1 & 66.57 & 0.389 & 0.764 & 1.3 & 92.53 & 1.41 \\
\hline 3 & 1 & -1 & 60 & 0.513 & 0.709 & 1.4 & 82.11 & 1.01 \\
\hline 4 & -1 & 0 & 47.14 & 0.258 & 0.824 & 1.21 & 95.16 & 1.1 \\
\hline 5 & 0 & 0 & 67.75 & 0.279 & 0.801 & 1.24 & 90.88 & 1.02 \\
\hline 6 & 1 & 0 & 72.71 & 0.451 & 0.713 & 1.4 & 84.97 & 1.13 \\
\hline 7 & -1 & 1 & 66.42 & 0.217 & 0.979 & 1.03 & 94 & 1.3 \\
\hline 8 & 0 & 1 & 75.28 & 0.259 & 0.982 & 1.01 & 88.19 & 1.32 \\
\hline 9 & 1 & 1 & 77.57 & 0.437 & 0.710 & 1.39 & 86.4 & 1.09 \\
\hline
\end{tabular}



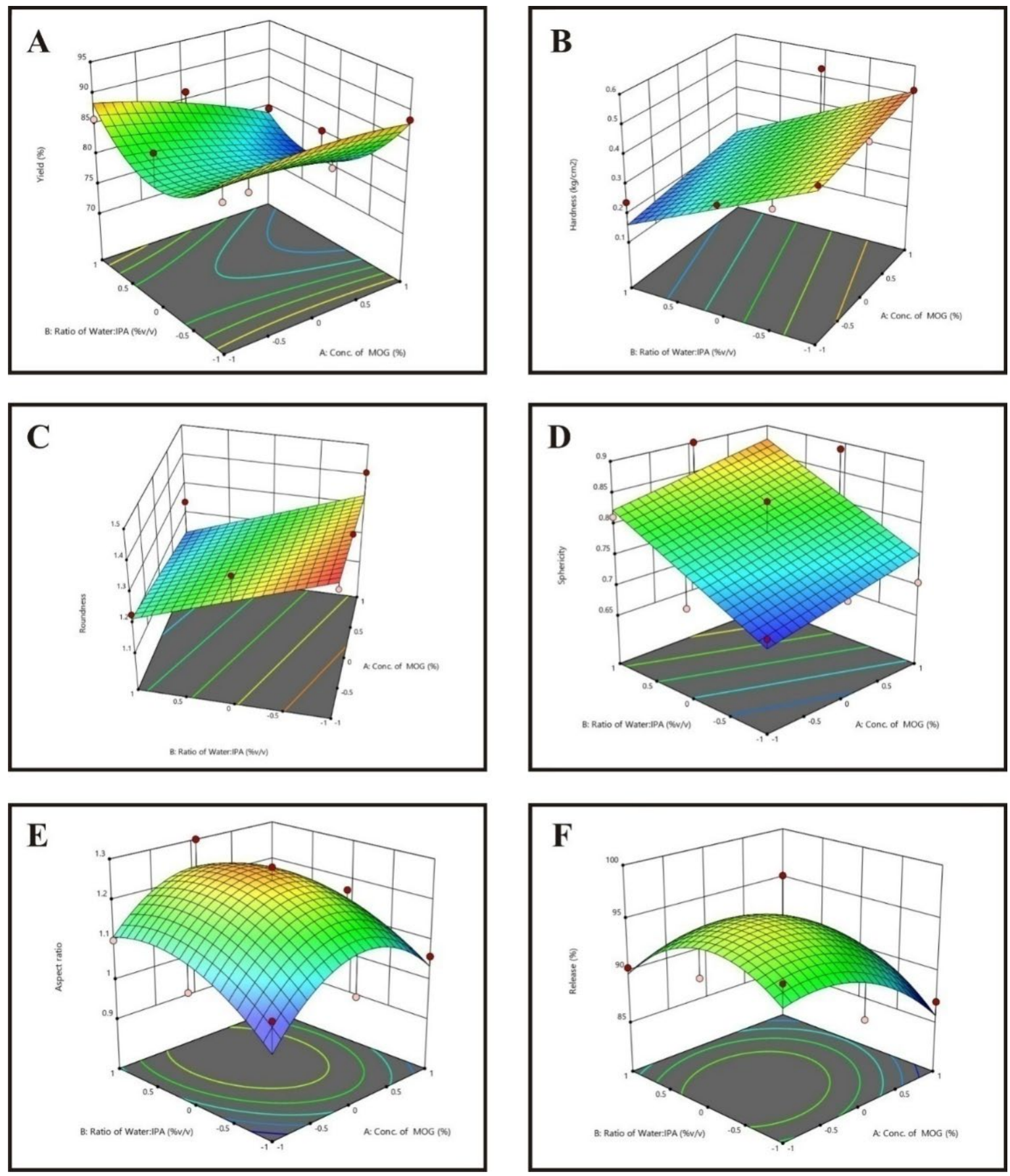

Figure 1. Response surface plots for MOG pellets A-Yield \%, B- Hardness C-Roundness, D- Sphericity, EAspect ratio, and F- Drug release \% 

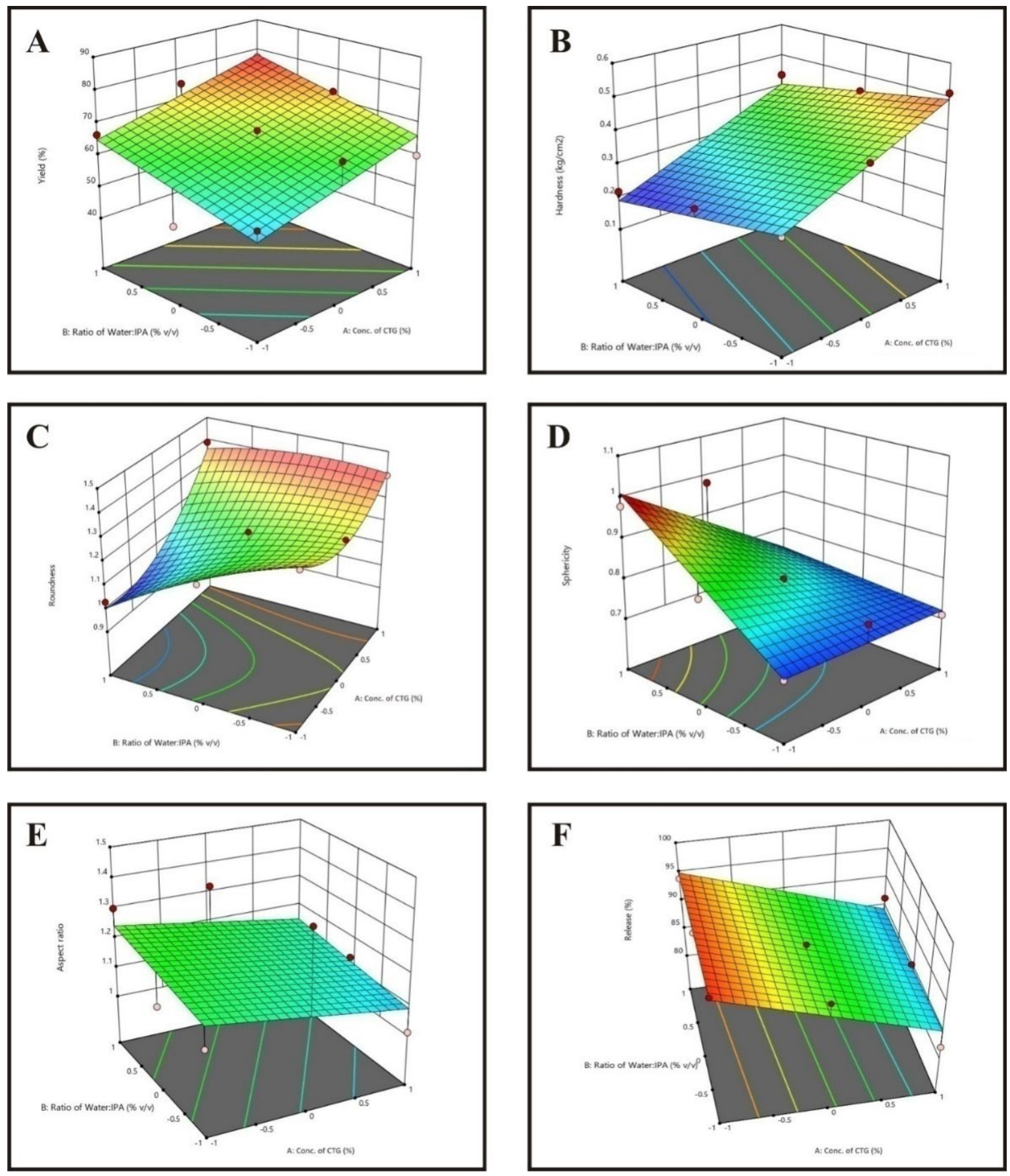

Figure 2. Response surface plots for CTG pellets A-Yield \%, B- Hardness C-Roundness, D- Sphericity, EAspect ratio, and F- Drug release \% 
Table 7. Results of pellets characterization

\begin{tabular}{|c|c|c|c|c|c|c|}
\hline Formulation & $\begin{array}{c}\text { Hardness } \\
\mathrm{Kg} / \mathrm{cm}^{2} \pm \mathrm{SD}\end{array}$ & $\begin{array}{c}\text { Sphericity } \\
\pm \mathrm{SD}\end{array}$ & $\begin{array}{c}\text { Roundness } \\
\pm \mathrm{SD}\end{array}$ & $\begin{array}{c}\text { Aspect ratio } \\
\pm S D\end{array}$ & $\begin{array}{c}\text { Release } \\
\pm \mathrm{SD}\end{array}$ & $\begin{array}{c}\text { Drug content } \\
\pm S D\end{array}$ \\
\hline $\mathrm{F} 1 \mathrm{M}$ & $0.456 \pm 0.024$ & $0.712 \pm 0.014$ & $1.40 \pm 0.046$ & $1.05 \pm 0.043$ & $94.11 \pm 2.10$ & $98.23 \pm 1.12$ \\
\hline $\mathrm{F} 2 \mathrm{M}$ & $0.463 \pm 0.011$ & $0.721 \pm 0.045$ & $1.38 \pm 0.051$ & $1.03 \pm 0.054$ & $88.12 \pm 1.54$ & $99.17 \pm 2.56$ \\
\hline F3M & $0.517 \pm 0.052$ & $0.705 \pm 0.055$ & $1.41 \pm 0.054$ & $1.06 \pm 0.063$ & $87.01 \pm 1.69$ & $96.52 \pm 2.14$ \\
\hline $\mathrm{F} 4 \mathrm{M}$ & $0.314 \pm 0.042$ & $0.709 \pm 0.011$ & $1.40 \pm 0.059$ & $1.04 \pm 0.021$ & $91.94 \pm 3.54$ & $95.21 \pm 3.12$ \\
\hline $\mathrm{F} 5 \mathrm{M}$ & $0.154 \pm 0.068$ & $0.837 \pm 0.013$ & $1.19 \pm 0.042$ & $1.28 \pm 0.024$ & $99.05 \pm 0.45$ & $98.56 \pm 2.10$ \\
\hline F6M & $0.532 \pm 0.035$ & $0.889 \pm 0.015$ & $1.12 \pm 0.023$ & $1.17 \pm 0.052$ & $89.10 \pm 2.59$ & $98.23 \pm 3.42$ \\
\hline F7M & $0.24 \pm 0.013$ & $0.812 \pm 0.024$ & $1.23 \pm 0.025$ & $1.10 \pm 0.063$ & $90.34 \pm 3.52$ & $92.15 \pm 3.14$ \\
\hline $\mathrm{F} 8 \mathrm{M}$ & $0.181 \pm 0.023$ & $0.900 \pm 0.052$ & $1.11 \pm 0.068$ & $1.30 \pm 0.045$ & $90.94 \pm 2.51$ & $98.68 \pm 1.23$ \\
\hline F9M & $0.181 \pm 0.045$ & $0.801 \pm 0.043$ & $1.24 \pm 0.073$ & $1.04 \pm 0.012$ & $87.40 \pm 1.37$ & $96.25 \pm 3.17$ \\
\hline F1C & $0.273 \pm 0.023$ & $0.715 \pm 0.023$ & $1.37 \pm 0.052$ & $1.11 \pm 0.032$ & $96.11 \pm 1.54$ & $88.52 \pm 2.12$ \\
\hline $\mathrm{F} 2 \mathrm{C}$ & $0.389 \pm 0.012$ & $0.764 \pm 0.012$ & $1.3 \pm 0.012$ & $1.41 \pm 0.019$ & $92.53 \pm 1.07$ & $91.25 \pm 1.63$ \\
\hline $\mathrm{F} 3 \mathrm{C}$ & $0.513 \pm 0.053$ & $0.709 \pm 0.018$ & $1.4 \pm 0.031$ & $1.01 \pm 0.023$ & $82.11 \pm 2.85$ & $96.86 \pm 3.12$ \\
\hline $\mathrm{F} 4 \mathrm{C}$ & $0.258 \pm 0.031$ & $0.824 \pm 0.016$ & $1.21 \pm 0.046$ & $1.1 \pm 0.031$ & $95.16 \pm 1.44$ & $92.36 \pm 1.68$ \\
\hline F5C & $0.279 \pm 0.021$ & $0.801 \pm 0.009$ & $1.24 \pm 0.017$ & $1.02 \pm 0.007$ & $90.88 \pm 1.71$ & $96.28 \pm 2.53$ \\
\hline F6C & $0.451 \pm 0.049$ & $0.713 \pm 0.025$ & $1.4 \pm 0.030$ & $1.13 \pm 0.013$ & $84.97 \pm 2.01$ & $97.53 \pm 5.25$ \\
\hline F7C & $0.217 \pm 0.028$ & $0.979 \pm 0.007$ & $1.03 \pm 0.019$ & $1.3 \pm 0.011$ & $94 \pm 1.15$ & $98.62 \pm 4.32$ \\
\hline F8C & $0.259 \pm 0.030$ & $0.982 \pm 0.010$ & $1.01 \pm 0.026$ & $1.32 \pm 0.041$ & $88.19 \pm 2.31$ & $95.47 \pm 0.97$ \\
\hline F9C & $0.437 \pm 0.015$ & $0.710 \pm 0.063$ & $1.39 \pm 0.009$ & $1.09 \pm 0.026$ & $86.4 \pm 1.30$ & $96.28 \pm 2.63$ \\
\hline
\end{tabular}

\section{Physical properties of pellets}

Percent production yield, hardness, sphericity, roundness, and aspect ratio are shown in table 6 . The optimized batch of pellets was found free-flowing. Approximately spherical shape formulation F8M exhibited sphericity, aspect ratio, and roundness $0.900 \pm 0.052$, $1.30 \pm 0.045$ and $1.11 \pm 0.0681 .30 \pm 0.045$, respectively, sphericity close to 1 indicates that spherical shape of pellets and roundness below 1.20 shows smooth surface and aspect ratio also gives an idea about the shape of pellets when it is close to 1 indicate more spherical pellets (Eriksson, Alderborn, Nyström, Podczeck, \& Newton, 1997; Podczeck, Rahman, \& Newton, 1999). Pellets prepared by extrusion-spheronisation, has been assessed by the analysis of the two-dimensional images in the form of an elongation ratio (direct microscopic measurement Formulation of F7C and F8C exhibited sphericity, aspect ratio, and roundness $0.979 \pm 0.007,1.3 \pm 0.011,1.03 \pm 0.019$ and $0.982 \pm 0.010$, $1.32 \pm 0.041$ and $1.01 \pm 0.026$ respectively. Drug content of different batches, as shown in Table 7 within the limit as official guidelines. 
Table 8. Flow properties of mesalamine MOG and CTG pellets

\begin{tabular}{|c|c|c|c|c|c|}
\hline Formulation & $\begin{array}{c}\text { Flow rate } \\
(\mathbf{g} / \mathbf{s e c}) \pm S D\end{array}$ & $\begin{array}{c}\text { Angle of repose }\left({ }^{\circ}\right) \\
\pm S D\end{array}$ & Formulation & $\begin{array}{c}\text { Flow rate } \\
(\mathbf{g} / \mathbf{s e c}) \pm S D\end{array}$ & $\begin{array}{c}\text { Angle of repose }()^{)} \\
\pm S D\end{array}$ \\
\hline F1M & $1.12 \pm 0.09$ & $25.63 \pm 1.12$ & F1C & $1.15 \pm 0.12$ & $25.16 \pm 0.97$ \\
\hline F2M & $1.06 \pm 0.12$ & $27.20 \pm 1.12$ & F2C & $1.18 \pm 1.17$ & $24.23 \pm 1.23$ \\
\hline F3M & $1.02 \pm 0.09$ & $22.45 \pm 1.07$ & F3C & $1.12 \pm 0.09$ & $24.17 \pm 1.17$ \\
\hline F4M & $1.03 \pm 0.67$ & $28.16 \pm 2.14$ & F4C & $1.07 \pm 0.32$ & $28.19 \pm 1.16$ \\
\hline F5M & $1.06 \pm 0.06$ & $27.07 \pm 0.08$ & F5C & $1.20 \pm 0.78$ & $22.43 \pm 1.08$ \\
\hline F6M & $1.07 \pm 0.11$ & $27.16 \pm 1.17$ & F6C & $1.10 \pm 0.29$ & $26.64 \pm 0.07$ \\
\hline F7M & $0.98 \pm 0.07$ & $29.15 \pm 1.18$ & F7C & $1.16 \pm 0.78$ & $24.27 \pm 0.17$ \\
\hline F8M & $1.20 \pm 0.11$ & $21.45 \pm 1.11$ & F8C & $1.23 \pm 0.36$ & $22.83 \pm 1.16$ \\
\hline F9M & $1.12 \pm 0.07$ & $24.12 \pm 0.17$ & F9C & $1.20 \pm 0.15$ & $23.27 \pm 1.13$ \\
\hline
\end{tabular}

\section{Drug Release of Uncoated Pellets}

The release pattern of MOG and CTG uncoated pellets in $0.1 \mathrm{~N} \mathrm{HCl}$ is shown in Figures 3 and 4. Optimized batch showed release in a sustained manner up to $2 \mathrm{~h}$. Release mechanism as per different pattern are shown in tables at S10 and S11 supplementary file, $\mathrm{R}^{2}$ values for a different pattern for optimized formulations F8M and F8C are Higuchi, Hixson Crowell, Korsmeyer Peppas zero-order, first-order models showed at S12 in the supplementary file.

For first-order release, $\mathrm{R}^{2}$ value for the optimized formulation was found 0.987 for both gums; in the case of Higuchi model $\mathrm{R}^{2}$ value for this model, for optimized formulations F8M and F8C 0.979 and 0.994 respectively, Hixson Crowell model observed for formulation F8M and F8C 0.887 and 0.981 and for Korsmeyer Peppas model of release for formulation $\mathrm{R}^{2}$ vales $\mathrm{F} 8 \mathrm{M}$ and $\mathrm{F} 8 \mathrm{C} 0.975$ and 0.994 respectively. Further investigation and for confirmation of release behavior $\mathrm{n}$ values were calculated and found to be in between 0.45 to 0.89 .

\section{Drug release of coated pellets}

The release behavior of Eudragit coated pellets were studied for optimized batches of MOG and CTG as shown in Figure 5, which showed that the initial lag phase of release at $\mathrm{pH}$ dissolution media simulated to upper GIT in $0.1 \mathrm{~N} \mathrm{HCl}$ for $2 \mathrm{~h}$ and phosphate buffer $\mathrm{pH} 6.8 \mathrm{2h}$ and release of drug observed phosphate buffer $\mathrm{pH} 7.4$ in a sustained manner for $4 \mathrm{~h}$.

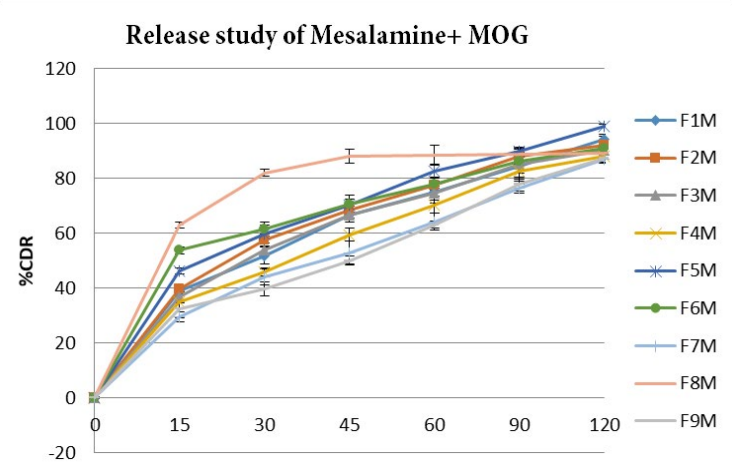

Figure 3. Dissolution study of mesalamine MOG uncoated pellets in $0.1 \mathrm{~N} \mathrm{HCl}$

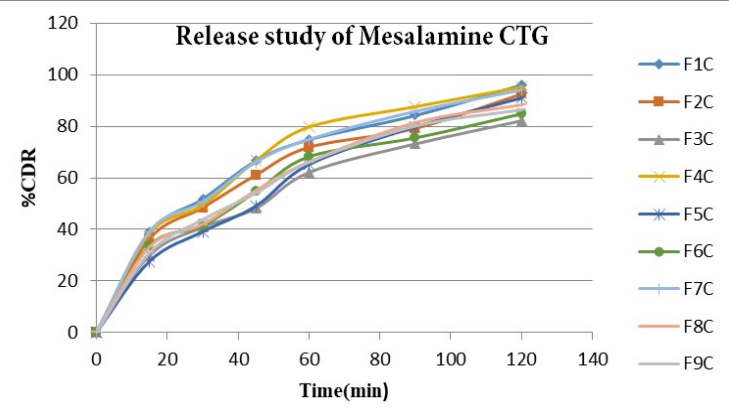

Figure 4. Dissolution study of mesalamine CTG uncoated pellets in $0.1 \mathrm{~N} \mathrm{HCl}$ 


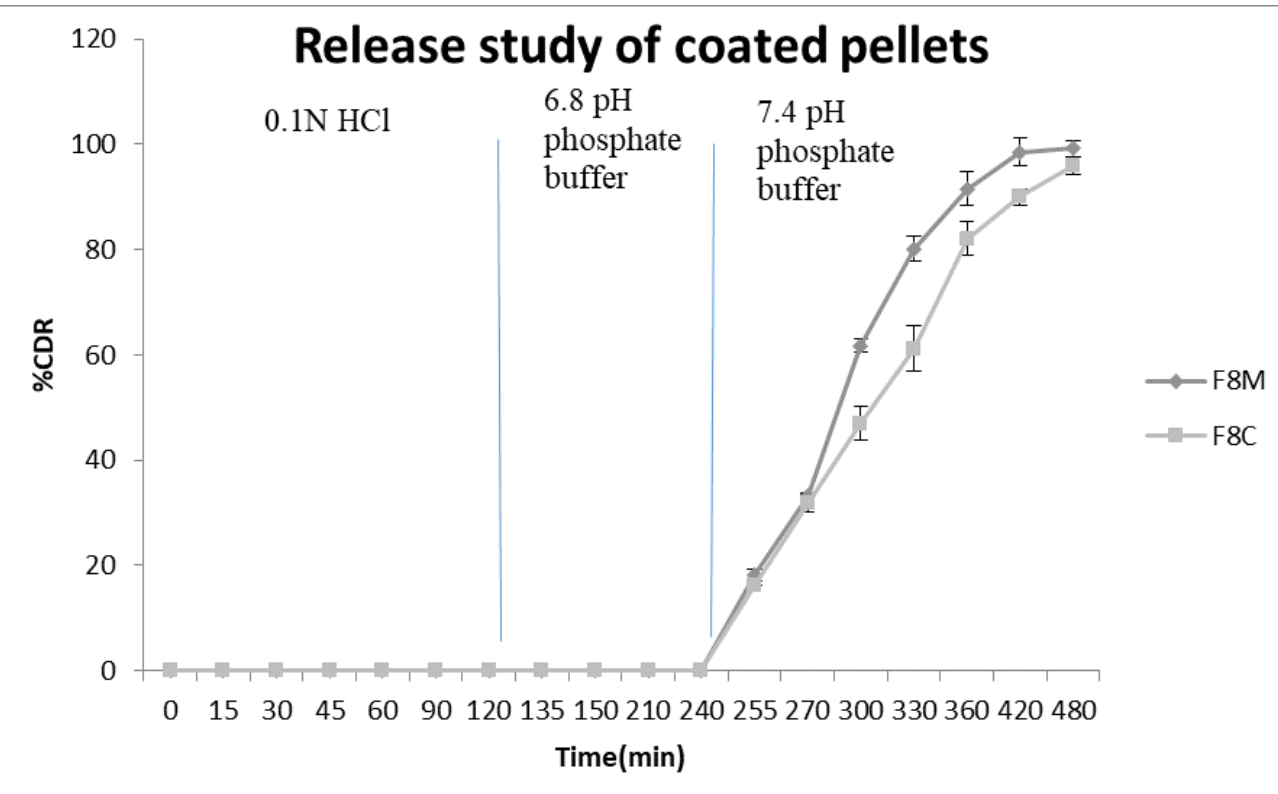

Figure 5. In vitro dissolution studies for coated pellets F8M and F8C, $2 \mathrm{~h}$ in $0.1 \mathrm{~N} \mathrm{HCl}, 2 \mathrm{~h} \mathrm{pH} 6.8$ phosphate buffer, and $4 \mathrm{~h}$ in $\mathrm{pH} 7.4$ phosphate buffer 

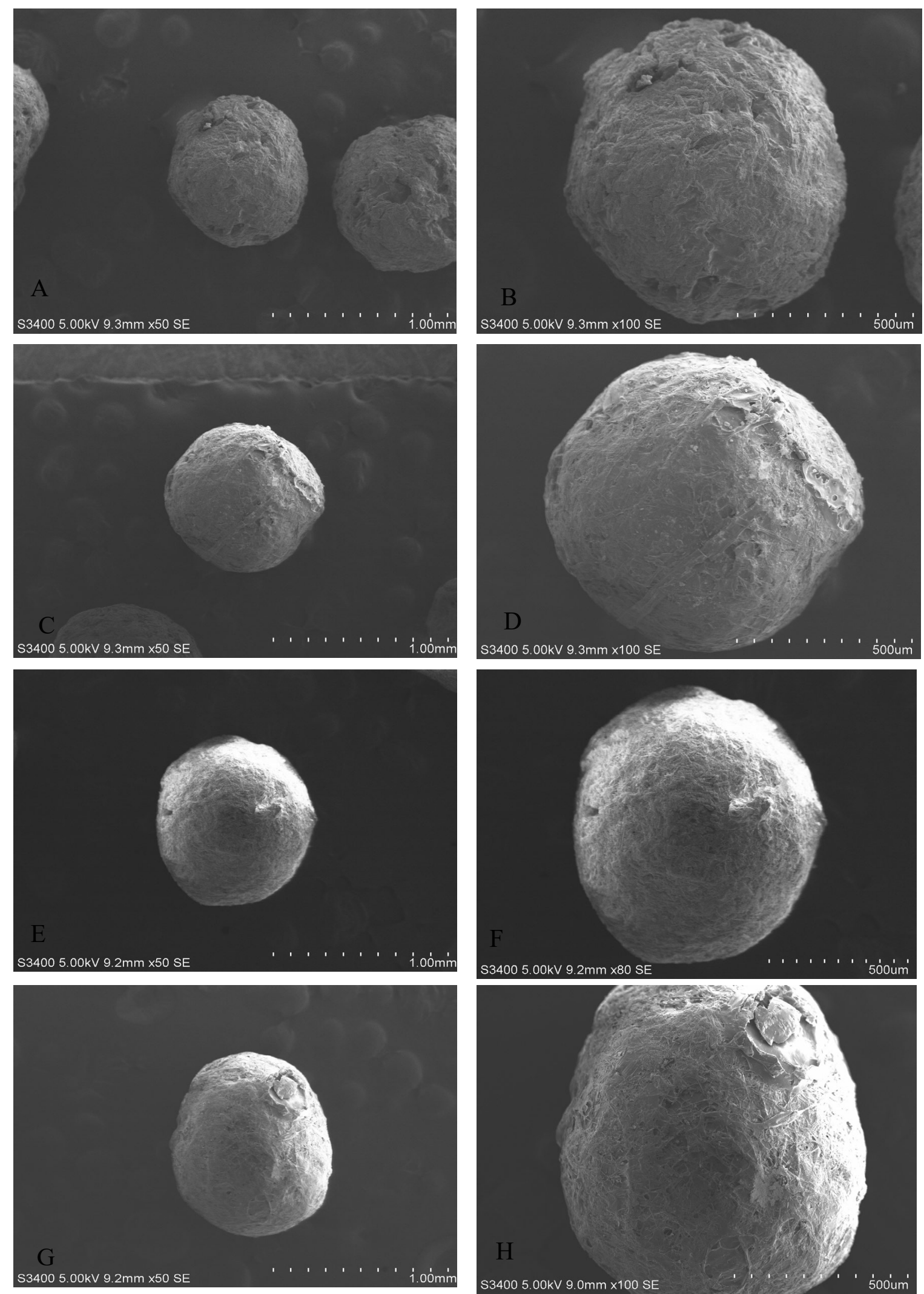

Figure 6. SEM images of uncoated and coated pellets at different magnifications A. Uncoated MOG pelletsX50 B. Uncoated MOG pelletsX100 C. Coated MOG pelletsX50 D. Coated MOG pelletsX100, E. Uncoated CTG pellets X50 F. Uncoated CTG pellets X80, G. Coated CTG pelletsX50, and H. Coated CTG pelletsX100 


\section{SEM analysis}

The SEM images with different magnifications indicated the difference between uncoated and coated pellets. The SEM analysis of pellets was found that pellets containing CTG showed a smooth surface as compared to MOG. In coated pellets, it is shown that uniform coating of polymer responsible for the release of drug at a specific $\mathrm{pH}$ value of the colonic site. In the image of pellets CTG ( $\mathrm{G}$ and $\mathrm{H}$ ) shows some broken parts of it might be during sampling of SEM.

\section{In vivo roentgenographic study}

An in vivo roentgenographic study was carried out in rabbits to evaluate targeting of enteric-coated pellets. Rabbits were used to study the targeting of pellets in the colonic site because the rabbit has anatomically and physiological similarities with the human sub- ject. X-ray examination observed at the different time points at the end of $1,2,4,5,7$, and $8 \mathrm{~h}$, in the first image $\mathrm{A}$ at the end of $1 \mathrm{~h}$ observed that pellets containing Barium sulfate highlighted at stomach region of the rabbit after some time interval up to the end of $2 \mathrm{~h}$, pellets were remained intact in the stomach then in image $\mathrm{C}$ and $\mathrm{D}$ indicates that pellets reached small intestine and size of highlighted pellets were same. Image at the end of 5 and $7 \mathrm{~h}$ it is shows that it reached up to large intestine and lastly at the end of $8 \mathrm{~h}$ very fewer pellets are observed it means that drug gets released at the colonic site at the favorable condition of the colon. The targeting pellets were observed in the present study number of pellets were observed at small and large intestinal parts, and after $7 \mathrm{~h}$ few pellets were depicted in Figure 7.

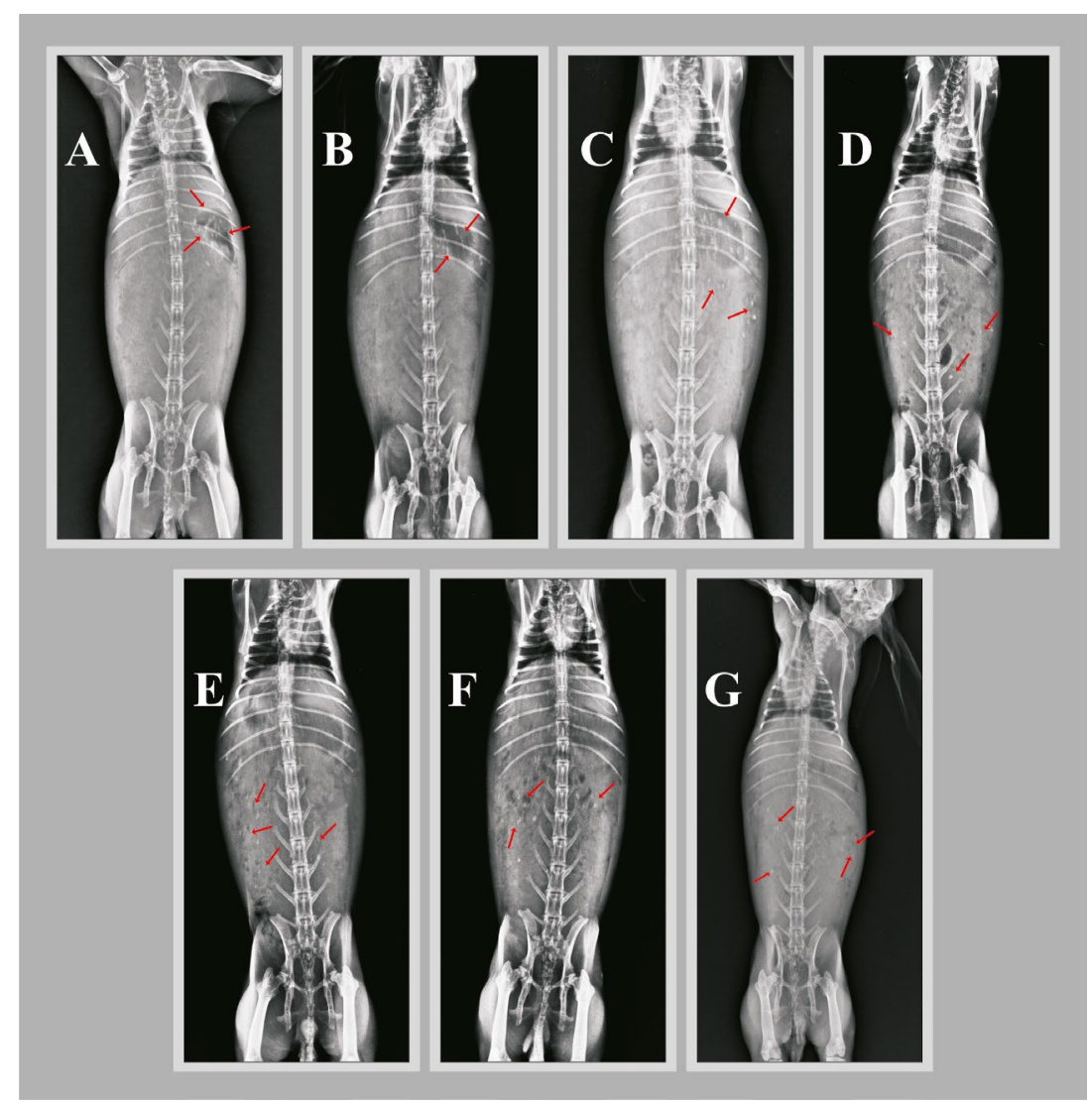

Figure 7. Roentgenographic study in rabbit (A-F) behavior of enteric-coated pellets A- Shows lighted pellets in stomach after $1 \mathrm{~h}$ of administration, B- after $2 \mathrm{~h}$ pellets at stomach $\mathrm{C}$ - at small intestine after $3 \mathrm{~h}$ pellets $\mathrm{D}$ - after $4 \mathrm{~h}$ pellets remain in the small intestine E-after $5 \mathrm{~h}$ pellets at the colonic site remain intact $\mathrm{F}$ - after $7 \mathrm{~h}$ decreases the size of pellets shown and G- after $8 \mathrm{~h}$ few numbers of pellets at the colonic site. 


\section{DISCUSSION}

Mesalamine pellets prepared in an optimum concentration of MOG and CTG gums with wetting solvent showed the controlled release of drugs at the colonic site when coated with Eudragit enteric polymer S100. Various characterization studies were performed before formulation and for optimization of batches which showed the relevant results as per hypothesis. In the FTIR study, drug and excipients revealed no interaction. All characteristic peaks of the mesalamine in FT-IR spectra of the physical mixture and pellets indicate a lack of chemical interaction in the drug and other excipients. Resulting spectra of mesalamine formulation compared with reference FT-IR spectra, no chemical interaction between drug and excipient was found (Kaffash, 2019). FTIR data also compared with mesalamine nanoparticles with chitosan, found that no remarkable changes observed in peaks of the functional group indicate that no interaction is happening (Seifirad, Karami, Shahsavari, Mirabbasi, \& Dorkoosh, 2016).

The DCS data for mesalamine pellets containing MOG observed a broad endothermic peak with a sharp peak of mesalamine at $283.93^{\circ} \mathrm{C}$, which revealed that lack of interaction of mesalamine and other excipients CTG showed the change in peaks intensity it could be polymorphic changes of mesalamine during extrusion and spheronization with CTG (Kaffash, 2019).

The Extrusion-spheronization process is desired to formulate of spherical particles of uniform size and proper shape, which facilitate the successful coating to control the release of drug at the desired site. In the present study, natural gums MOG and CTG were used for the preparation of pellets based on of their binding and release retardants properties; optimization study was done for the selection of the final batch with desired properties. In optimization process found that not only wetting liquid but also concentrations of gums are very important during formulation development. The preliminary investi- gation found that at higher concentrations of gums, dumbbell-shaped pellets were formed, and at lower concentrations, less binding ability was observed. The second factor, the ratio of wetting liquid; sticky mass, was observed when water alone is used as wetting solvent, which causes difficulties during extrusion and spheronization. These difficulties were overcome by adding non-aqueous solvent (IPA) in different ratios with water. The factorial study was carried out to find the significant effect of most influencing factors which the different concentrations of gums and wetting liquid on responses include release, yield, sphericity, roundness, and hardness, as mentioned in Table 5 and 6. The study was performed to select of the best levels of independent variables, and on that basis, the final optimized formulation batch was selected. Nine batches were made with each gum, and all responses were observed, which were fitted in a different model. From that basis, we found the optimum level of the independent variable. In optimization studies, various polynomial equations were obtained, as shown in table S2 for a relationship of factor and responses. The positive sign indicates a synergistic effect, and the negative sign shows the antagonistic effect (Bodea \& Leucuta, 1997). As discussed above, IPA is added to water to reduce hydration of both gums. Effect in hydration change by adding IPA can be graphically represented by response surface curve as shown in Figure 1, and 2 and it can be clearly understood by the 3D bar chart provided in supplementary files $\mathrm{S} 8$ and S9. As per the graph (Figure $1 \& 2$ ), the effect of different ratios of IPA and concentration of gums on various properties of pellets; \% yield, hardness, roundness, sphericity, aspect ratio, and \% drug release of pellets to the identification of the significant effect of most influencing factors on responses and selection of best levels for independent variables for optimized formulation. Effect of independent variables on various parameters firstly hardness of pellets formulation according to both curves it seems that increasing concentration of IPA leads to decreasing hardness of pel- 
lets and reverse for the concentration of gum. Pellets with CTG formulation, hardness is markedly affected by the concentration of gum rather than the solvent concentration as CTG has a branch chain of polysaccharides (Tiwari, 2019; Tiwari \& Prabaharan, 2010) as observed in formulation F3C, F6C, and F9C. In the case of MOG linear chain molecule d-Galactose residues (Singh \& Kumar, 2018b; Tiwari, 2019), so it does not show the marked effect on hardness.

The sphericity is more affected with the concentration of gum. In contrast, the ratio of solvent at a moderately affected, concentration of gum, and high concentration of IPA shows good sphericity, roundness, and aspect ratio.

Physical properties, these data showed that a pellet with a higher concentration of gum becomes of irregular shaped and the same irregularity in shape had appeared when IPA was used in less concentration. The optimized formulation F8M which contains MOG, and F8C, which contains CTG, were selected based on the responses obtained from physical properties after optimization study on all formulations.

The release pattern of MOG and CTG uncoated pellets in $0.1 \mathrm{~N} \mathrm{HCl}$ was observed in a sustained manner up to $2 \mathrm{~h}$ both natural gum formed matrix with the drug, which retards release of the drug. For a better understanding of the release mechanism of the drug from formulation, different models were studied such as zero-order, first-order, Higuchi, Hixson Crowell, and Korsmeyer Peppas. Zero-order indicates that release of drug in a controlled manner which is independent of the concentration of the drug, first-order shows release dependant on the initial concentration of drug. It can show a sustained pattern of release it present study drug release from matrix of gum observed release in a sustained manner (Bruschi, 2015). In the case of the Higuchi model, it indicates that the release of the drug from the matrix and swelling of the matrix is negligible. Also release of the drug is unidirectional with the diffusivity of the drug be- ing constant (Dubernet, Benoit, Peppas, \& Puisieux, 1990). Hixson Crowell shows surface decreases proportionally with time observed. Korsmeyer Peppas model indicates that release of drug with diffusion or solvent transport, for further understanding about actual release pattern ' $n$ ' value was calculated to find actual release behavior of drug from polymeric matrix if $\mathrm{n}$ value is 0.5 indicates diffusion release and when $\mathrm{n}=1$ model shows release pattern in non-fickian due to swelling and relaxation of the internal structure of the polymer and if values $0.5<\mathrm{n}<1$ it indicates release in swelling and diffusion pattern. The $\mathrm{n}$ value was calculated for optimized batches F8M, and F8C were found to be between 0.45 to 0.89 ; it means that the release pattern of the drug is diffusion and swelling of matrix pellets due to the presence of hydrophilic gums (Korsmeyer, Gurny, Doelker, Buri, \& Peppas, 1983; Santos, 2004). Uncoated pellets of MOG and CTG showed release in $0.1 \mathrm{~N} \mathrm{HCl}$ in a sustained manner due to water-soluble matrix swelling. So coating of formulation with $\mathrm{pH}$-dependant polymer was done to achieve release at the colonic site in up to $8 \mathrm{~h}$.

CTG imparted the smooth surface on the pellets as compared to MOG, which was revealed with SEM analysis as MOG showed the porous nature, which could be because of evaporation of wetting liquid (especially IPA) from the surface of pellets. In coated pellets with Eudragit gave the uniform coat responsible for releasing the drug at a specific $\mathrm{pH}$ value of the colonic site. However, one of the pictures showed the broken surface of coated pellet, this could be because of sampling during SEM.

In vivo roentgenographic $\mathrm{X}$-ray examinations were done to the observed movement of pellets in GIT. In vivo evaluation showed that pellets coated with Eudragit S100 at various time intervals moved without disintegration and reached up to the colon at the end of $8 \mathrm{~h}$ very fewer pellets were observed, which means that the drug gets released at the colonic site at the favorable condition. Comparative study X-ray 
examination Tuğcu-Demiroz found that intact matrix tablet up to colon and then it disintegrates at colonic site same images observed for X-ray examination in rabbit (Tuğcu-Demiröz, 2004) also in CODES type formulation shown no significant changes in size and shape of formulation(Singh \& Pathak, 2015)each at three different levels and the dependent variable was $\% \mathrm{CDR}$ at $12 \mathrm{~h}$. The core tablets were evaluated for pharmacopoeial and non-pharmacopoeial test and coated with optimized levels of Eudragit E100 followed by HPMC K15 and finally with Eudragit S100. The in vitro drug release study of F1-F9 was carried out by change over media method $(0.1 \mathrm{~N} \mathrm{HCl}$ buffer, pH 1.2, phosphate buffer, $\mathrm{pH} 7.4$ and phosphate buffer, pH 6.8 with enzyme b-galactosidase 120 IU.

\section{CONCLUSION}

It has been concluded from the present research work that optimization of physical properties such as hardness, sphericity, and release of pellets with the optimized concentration of gums (MOG 10\% and CTG 7.5\%) and wetting solvent (water: IPA $=80: 20$ ) by using extrusion and spheronization techniques led to sustaining release of drugs, which is proved to non-fickian release in nature due to swelling of gum by forming the hydrophilic matrix. Further, prevention of disintegration and absorption in upper GIT, uniform coating because of spherical nature of pellets with Eudragit S100 helped to target the colonic site which is confirmed by in vitro dissolution method and in vivo targeting in rabbit which ensured with pellets which were having radio-opaque substance, which was identified on $\mathrm{x}$-ray at colonic site.

As to say as advantages, spheronization and extrusion method was proved to have economized, whereas natural gums used to control release which added advantage as being as inert and biocompatible. This formulation can have a further scope at industrial scales to reduce the side effects of synthetic polymer and make it more biocompatible with the body.

\section{CONFLICT OF INTEREST}

All the authors of this article declared no conflict of interest.

\section{AUTHOR CONTRIBUTION STATEMENT}

Investigation, literature research, experimenting, analysis, interpretation of the data, statistics, preparing the study text and writing the original draft (Rijawan Rajjak Pathan). Developing a hypothesis, reviewing the text, resources, and supervision (Aquil-ur-Rahim Siddiqui)

\section{REFERENCES}

Al-Hashimi, N., Begg, N., Alany, R. G., Hassanin, H., \& Elshaer, A. (2018). Oral Modified Release Multiple-Unit Particulate Systems: Compressed Pellets, Microparticles and Nanoparticles. Pharmaceutics, 10(4), 176. Retrieved from https://doi. org/10.3390/pharmaceutics10040176

Auriemma, G., Mencherini, T., Russo, P., Stigliani, M., Aquino, R. P., \& Del Gaudio, P. (2013). Prilling for the development of multi-particulate colon drug delivery systems: Pectin vs. pectin-alginate beads. Carbohydrate Polymers, 92(1), 367-373. Retrieved from https://doi.org/10.1016/j.carbpol.2012.09.056

Bendas, E. R., Christensen, J. M., \& Ayres, J. W. (2010). Development and in vitro evaluation of mesalamine delayed release pellets and tableted reservoir-type pellets. Drug Development and Industrial Pharmacy, 36(4), 393-404. Retrieved from https://doi.org/10.3109/03639040903213717

Bruschi, M. L. (2015). Mathematical models of drug release. In Strategies to Modify the Drug Release from Pharmaceutical Systems (pp. 63-86). Elsevier. Retrieved 22 March 2021 from https://doi. org/10.1016/B978-0-08-100092-2.00005-9

Bodea, A., \& Leucuta, S. E. (1997). Optimization of propranolol hydrochloride sustained release pellets using a factorial design. International Journal of Pharmaceutics, 154(1), 49-57. Retrieved from https://doi.org/10.1016/S0378-5173(97)00114-2 
Čalija, B., Cekić, N., Savić, S., Daniels, R., Marković, B., \& Milić, J. (2013). pH-sensitive microparticles for oral drug delivery based on alginate/oligochitosan/Eudragit ${ }^{\oplus}$ L100-55 "sandwich" polyelectrolyte complex. Colloids and Surfaces B: Biointerfaces, 110, 395-402. Retrieved from https://doi. org/10.1016/j.colsurfb.2013.05.016

Cao, Q., Jin, L., Ding, Y., Zhang, Y., \& Xu, X. (2016). A novel pH\&ndash;enzyme-dependent mesalamine colon-specific delivery system. Drug Design, Development and Therapy, 2021. Retrieved from https://doi.org/10.2147/DDDT.S107283

Costa, F. O., Sousa, J. J. S., Pais, A. A. C. C., \& Formosinho, S. J. (2003). Comparison of dissolution profiles of Ibuprofen pellets. Journal of Controlled Release, 89(2), 199-212. Retrieved from https:// doi.org/10.1016/S0168-3659(03)00033-6

Deshpande, R. D., Gowda, D. V., \& Mahammed, N. (2013). Design of Pistacia lentiscus (mastic gum) controlled release spheroids and investigating the influence of roll compaction. Industrial Crops and Products, 44, 603-610. Retrieved from https://doi. org/10.1016/j.indcrop.2012.09.014

Dubernet, C., Benoit, J. P., Peppas, N. A., \& Puisieux, F. (1990). Ibuprofen-loaded ethylcellulose microspheres: Release studies and analysis of the matrix structure through the Higuchi model. Journal of Microencapsulation, 7(4), 555-565. Retrieved from https://doi.org/10.3109/02652049009040479

Eriksson, M., Alderborn, G., Nyström, C., Podczeck, F., \& Newton, J. M. (1997). Comparison between and evaluation of some methods for the assessment of the sphericity of pellets. International Journal of Pharmaceutics, 148(2), 149-154. Retrieved from https://doi.org/10.1016/S0378-5173(96)04845-4

Friciu, M. M., Le, T. C., Ispas-Szabo, P., \& Mateescu, M. A.(2013). Carboxymethyl starch and lecithin complex as matrix for targeted drug delivery: I. Monolithic mesalamine forms for colon delivery. European Journal of Pharmaceutics and Biophar- maceutics, 85(3), 521-530. Retrieved from https:// doi.org/10.1016/j.ejpb.2013.03.007

Hamedelniel, E. I., Bajdik, J., \& Pintye-Hódi, K. (2010). Optimization of preparation of matrix pellets containing ethylcellulose. Chemical Engineering and Processing: Process Intensification, 49(1), 120-124. Retrieved from https://doi. org/10.1016/j.cep.2009.12.002

Hanauer, S. B. (1998). Dose-ranging study of mesalamine (PENTASA) enemas in the treatment of acute ulcerative proctosigmoiditis: Results of a multicentered placebo-controlled trial. Inflammatory Bowel Diseases, 4(2), 79-83.

Hanauer, S., Schwartz, J., Robinson, M., Roufail, W., Arora, S., Cello, J., \& Safdi, M. (1993). Mesalamine capsules for treatment of active ulcerative colitis: Results of a controlled trial. American Journal of Gastroenterology (Springer Nature), 88(8).

Hedin, C., Whelan, K., \& Lindsay, J. O. (2007). Evidence for the use of probiotics and prebiotics in inflammatory bowel disease: a review of clinical trials. Proceedings of the Nutrition Society, 66(3), 307-315. Retrieved from https://doi.org/10.1017/ S0029665107005563

Hileman, G. A., Goskonda, S. R., Spalitto, A. J., \& Upadrashta, S. M. (1993). Response surface optimization of high dose pellets by extrusion and spheronization. International Journal of Pharmaceutics, 100(1-3), 71-79. Retrieved from https:// doi.org/10.1016/0378-5173(93)90077-S

Ige, P. P., \& Gattani, S. G. (2012). Design and in vitro and in vivo characterization of mucoadhesive matrix pellets of metformin hydrochloride for oral controlled release: A technical note. Archives of Pharmacal Research, 35(3), 487-498. Retrieved from https://doi.org/10.1007/s12272-012-0312-7

Isaac, G. S. (2018). In Pellets: a general overview, Pharmaceutical Pelletization Technology. informa health care, New York, London. 
Joshi, A., Pund, S., Nivsarkar, M., Vasu, K., \& Shishoo, C. (2008). Dissolution test for site-specific release isoniazid pellets in USP apparatus 3 (reciprocating cylinder): Optimization using response surface methodology. European Journal of Pharmaceutics and Biopharmaceutics, 69(2), 769-775. Retrieved from https://doi.org/10.1016/j.ejpb.2007.11.020

Kaffash, E., Saremnejad, F., Abbaspour, M., Mohajeri, S. A., Garekani, H. A., Jafarian, A. H., ... Nokhodchi, A. (2019). Statistical optimization of alginate-based oral dosage form of 5-aminosalicylic acid aimed to colonic delivery: In vitro and in vivo evaluation. Journal of Drug Delivery Science and Technology, 52, 177-188. Retrieved from https:// doi.org/10.1016/j.jddst.2019.04.006

Kakar, S., Batra, D., \& Singh, R. (2013). Preparation and evaluation of magnetic microspheres of mesalamine (5-aminosalicylic acid) for colon drug delivery. Journal of Acute Disease, 2(3), 226-231. Retrieved from https://doi.org/10.1016/S22216189(13)60132-8

Kam, L., Cohen, H., Dooley, C., Rubin, P., \& Orchard, J. (1996). A comparison of mesalamine suspension enema and oral sulfasalazine for treatment of active distal ulcerative colitis in adults. American Journal of Gastroenterology (Springer Nature), 91(7).

Korsmeyer, R. W., Gurny, R., Doelker, E., Buri, P., \& Peppas, N. A. (1983). Mechanisms of solute release from porous hydrophilic polymers. International Journal of Pharmaceutics, 15(1), 25-35. Retrieved from https://doi.org/10.1016/03785173(83)90064-9

Liu, L., Fishman, M. L., Kost, J., \& Hicks, K. B. (2003). Pectin-based systems for colon-specific drug delivery via oral route. Biomaterials, 24(19), 33333343. Retrieved from https://doi.org/10.1016/ S0142-9612(03)00213-8
Lorenzo-Lamosa, M. L., Remuñán-López, C., Vila-Jato, J. L., \& Alonso, M. J. (1998). Design of microencapsulated chitosan microspheres for colonic drug delivery. Journal of Controlled Release, 52(1-2), 109-118. Retrieved from https://doi.org/10.1016/ S0168-3659(97)00203-4

Mezreb, N., Charrueau, C., Boy, P., Allain, P., \& Chaumeil, J. C. (2004). Production of Carbopol ${ }^{\circledR}$ 974P and Carbopol ${ }^{\circ}$ 971P Pellets by ExtrusionSpheronization: Optimization of the Processing Parameters and Water Content. Drug Development and Industrial Pharmacy, 30(5), 481-490. Retrieved from https://doi.org/10.1081/DDC120037476

Mohanta, S., Singh, S. K., Kumar, B., Gulati, M., Kumar, R., Yadav, A. K., ... Pandey, N. K. (2019). Efficacy of co-administration of modified apple polysaccharide and probiotics in guar gum-Eudragit S100 based mesalamine mini tablets: A novel approach in treating ulcerative colitis. International Journal of Biological Macromolecules, 126, 427435. Retrieved from https://doi.org/10.1016/j. ijbiomac.2018.12.154

Muley, S., Nandgude, T., \& Poddar, S. (2016). Extrusion-spheronization a promising pelletization technique: In-depth review. Asian Journal of Pharmaceutical Sciences, 11(6), 684-699. Retrieved from https://doi.org/10.1016/j.ajps.2016.08.001

Muley, S. S., Nandgude, T., \& Poddar, S. (2017). Formulation and Optimization of Lansoprazole Pellets Using Factorial Design Prepared by Extrusion-Spheronization Technique Using Carboxymethyl Tamarind Kernel Powder. Recent Patents on Drug Delivery \& Formulation, 11(1). Retrieved 9 February 2021 from https://doi.org/1 $0.2174 / 1872211311666170113150248$ 
Parmar, C., Parikh, K., Mundada, P., Bhavsar, D., \& Sawant, K. (2018). Formulation and optimization of enteric coated bilayer tablets of mesalamine by RSM: In vitro - In vivo investigations and roentogenographic study. Journal of Drug Delivery Science and Technology, 44, 388-398. Retrieved from https://doi.org/10.1016/j.jddst.2018.01.008

Patel, M. M., \& Amin, A. F. (2011). Process, optimization and characterization of mebeverine hydrochloride loaded guar gum microspheres for irritable bowel syndrome. Carbohydrate Polymers, 86(2), 536-545. Retrieved from https://doi. org/10.1016/j.carbpol.2011.04.068

Patel, M. M., Shah, T. J., Amin, A. F., \& Shah, N. N. (2009). Design, Development and Optimization of a Novel Time and pH-Dependent Colon Targeted Drug Delivery System. Pharmaceutical Development and Technology, 14(1), 65-72. Retrieved from https://doi.org/10.1080/10837450802409412

Paterakis, P. G., Korakianiti, E. S., Dallas, P. P., \& Rekkas, D. M. (2002). Evaluation and simultaneous optimization of some pellets characteristics using a 33 factorial design and the desirability function. International Journal of Pharmaceutics, 248(1-2), 51-60. Retrieved from https://doi.org/10.1016/ S0378-5173(02)00341-1

Pawar, P. K., \& Gautam, C. (2016). Design, optimization and evaluation of mesalamine matrix tablet for colon drug delivery system. Journal of Pharmaceutical Investigation, 46(1), 67-78. Retrieved from https://doi.org/10.1007/s40005-015-0214-Z

Podczeck, F., Rahman, S. R., \& Newton, J. M. (1999). Evaluation of a standardised procedure to assess the shape of pellets using image analysis. International Journal of Pharmaceutics, 192(2), 123-138. Retrieved from https://doi.org/10.1016/S03785173(99)00302-6
Pund, S., Joshi, A., Vasu, K., Nivsarkar, M., \& Shishoo, C. (2010). Multivariate optimization of formulation and process variables influencing physico-mechanical characteristics of site-specific release isoniazid pellets. International Journal of Pharmaceutics, 388(1-2), 64-72. Retrieved from https://doi.org/10.1016/j.ijpharm.2009.12.034

Quinteros, D. A., Manzo, R. H., \& Allemandi, D. A. (2010). Design of a colonic delivery system based on cationic polymethacrylate (Eudragit E100)-mesalamine complexes. Drug Delivery, 17(4), 208-213. Retrieved from https://doi. org/10.3109/10717541003667806

Safdi, M., DeMicco, M., Sninsky, C., Banks, P., Wruble, L., Deren, J., ... Fleishman, C. (1997). A DoubleBlind Comparison of Oral versus Rectal mesalamine versus Combination Therapy in the Treatment of Distal Ulcerative Colitis. American Journal of Gastroenterology (Springer Nature), 92(10).

Santos, H., Veiga, F., Pina, M. E., \& Sousa, J. J. (2004). Compaction, compression and drug release characteristics of xanthan gum pellets of different compositions. European Journal of Pharmaceutical Sciences, 21(2-3), 271-281. Retrieved from https://doi.org/10.1016/j.ejps.2003.10.016

Seifirad, S., Karami, H., Shahsavari, S., Mirabbasi, F., \& Dorkoosh, F. A. (2016). Design and Characterization of Mesalamine Loaded Nanoparticles for Controlled Delivery System, 10.

Shaikh, M. S., \& Kale, M. A. (2020). Formulation and molecular docking simulation study of luliconazole nanosuspension-based nanogel for transdermal drug delivery using modified polymer. Materials Today Chemistry, 18, 100364. Retrieved from https://doi.org/10.1016/j.mtchem.2020.100364

Singh, A. K., \& Pathak, K. (2015). Colon specific CODES based Piroxicam tablet for colon targeting: statistical optimization, in vivo roentgenography and stability assessment. Pharmaceutical Development and Technology, 20(2), 237-245. Retrieved from https:// doi.org/10.3109/10837450.2013.860549 
Singh, B., \& Kumar, A. (2018a). Hydrogel formation by radiation induced crosslinked copolymerization of acrylamide onto moringa gum for use in drug delivery applications. Carbohydrate Polymers, 200, 262-270. Retrieved from https://doi. org/10.1016/j.carbpol.2018.08.018

Singh, B., \& Kumar, A. (2018b). Network formation of Moringa oleifera gum by radiation induced crosslinking: Evaluation of drug delivery, network parameters and biomedical properties. International Journal of Biological Macromolecules, 108, 477488. Retrieved from https://doi.org/10.1016/j. ijbiomac.2017.12.041

Singh, S. K., Reddy, I. K., \& Khan, M. A. (1996). Optimization and characterization of controlled release pellets coated with an experimental latex: II. Cationic drug. International Journal of Pharmaceutics, 141(1-2), 179-195. Retrieved from https://doi.org/10.1016/0378-5173(96)04635-2

Singhal, A., Daud, A., Jarald, E., \& Showkat, A. (2012). In vitro evaluation of Moringa oleifera gum for colon- specific drug delivery. International Journal of Pharmaceutical Investigation, 2(1), 48. Retrieved from https://doi.org/10.4103/2230-973X.96926

Sinha, V. R., \& Kumria, R. (2001a). Polysaccharides in colon-specific drug delivery. International Journal of Pharmaceutics, 224(1-2), 19-38. Retrieved from https://doi.org/10.1016/S0378-5173(01)00720-7

Sinha, V.R., \& Kumria, R. (2001b). Colonic drug delivery: prodrug approach. Pharm Res,18(5), 55764. https://doi.org/10.1023/a:1011033121528

Stolk, L. M. L., Rietbroek, R., Wiltink, E. H., \& Tukker, J. J. (1990). Dissolution profiles of mesalazine formulationsin vitro. Pharmaceutisch Weekblad Scientific Edition, 12(5), 200-204. Retrieved from https://doi.org/10.1007/BF01980047
Tho, I., Sande, S. A., \& Kleinebudde, P. (2002). Pectinic acid, a novel excipient for production of pellets by extrusion/spheronisation: preliminary studies. European Journal of Pharmaceutics and Biopharmaceutics, 54(1), 95-99. Retrieved from https:// doi.org/10.1016/S0939-6411(02)00048-6

Tiwari, A., Verma, A., Panda, P. K., Saraf, S., Jain, A., \& Jain, S. K. (2019). Stimuli-responsive polysaccharides for colon-targeted drug delivery. In Stimuli Responsive Polymeric Nanocarriers for Drug Delivery Applications (pp. 547-566). Elsevier. Retrieved 29 May 2021 from https://doi.org/10.1016/ B978-0-08-101995-5.00022-2

Tiwari, A., \& Prabaharan, M. (2010). An Amphiphilic Nanocarrier Based on Guar Gum-graft-Poly $(\varepsilon-$ caprolactone) for Potential Drug-Delivery Applications. Journal of Biomaterials Science, Polymer Edition, 21(6-7), 937-949. Retrieved from https:// doi.org/10.1163/156856209X452278

Tuğcu-Demiröz, F., Acartürk, F., Takka, S., \& Konuş-Boyunağa, Ö. (2004). In-vitro and In-vivo Evaluation of Mesalazine-Guar Gum Matrix Tablets for Colonic Drug Delivery. Journal of Drug Targeting, 12(2), 105-112. Retrieved from https:// doi.org/10.1080/10611860410001693751

Tuğcu-Demiröz, F., Acartürk, F., Takka, S., \& Konuş-Boyunağa, Ö. (2007). Evaluation of alginate based mesalazine tablets for intestinal drug delivery. European Journal of Pharmaceutics and Biopharmaceutics, 67(2), 491-497. Retrieved from https://doi.org/10.1016/j.ejpb.2007.03.003 